\title{
Organo-nitrogen Carcinogen
}

National Cancer Institute

\section{Source}

National Cancer Institute. Organo-nitrogen Carcinogen. NCI Thesaurus. Code C45176.

An org anic carcinogen having a C-N bond incorporated in its structure. ( $\mathrm{NCl05)}$ 